See Article page 84

\section{Commentary: Endoaortic balloon occlusion for minimally invasive mitral valve surgery: An empowering alternative}

\author{
Jake L. Rosen, BA, and T. Sloane Guy, MD, MBA
}

The message displayed by Drs Bates and Chitwood ${ }^{1}$ offers comprehensive insight into the advantages of the transthoracic crossclamp, addressing concerns regarding safety and efficacy of the clamp in relation to endoaortic balloon occlusion (EABO). ${ }^{1}$ The transthoracic clamp modality mimics that of an open technique, allowing for antegrade placement of a cardioplegia catheter. Because of its reproducibility and similarity to standard techniques, the authors argue that within minimally invasive and robotic programs, the clamp makes for a less-steep learning curve and easier team adoption. However, the expanding scope of robotic mitral valve surgery indicates further discussion regarding even less-invasive alternatives, such as that enabled by EABO. $^{2}$

$\mathrm{EABO}$ has been invaluable in our experience with robotic mitral valve surgery. Past studies have indicated noninferiority in outcomes of EABO to transthoracic crossclamping; Malvindi and colleagues ${ }^{3}$ revealed no statistically significant difference in postoperative complications, hospital length-of-stay, or in-hospital mortality. A large systematic review on the comparison of EABO to transthoracic clamping also supports the viability of EABO, with no significant difference in specific postoperative cardiovascular outcomes (ie, stroke and 30-day mortality). ${ }^{4}$

From the Division of Cardiovascular Surgery, Department of Surgery, Thomas Jefferson University, Philadelphia, Pa.

Disclosures: Dr Guy is a consultant for Edwards Lifesciences, Medtronic, and a case observation site and Proctor for Intuitive Surgical. Mr Rosen reported no conflicts of interest.

The Journal policy requires editors and reviewers to disclose conflicts of interest and to decline handling or reviewing manuscripts for which they may have a conflict of interest. The editors and reviewers of this article have no conflicts of interest.

Received for publication Oct 4, 2021; revisions received Oct 4, 2021; accepted for publication Oct 8, 2021; available ahead of print Oct 13, 2021.

Address for reprints: T. Sloane Guy, MD, MBA, 1025 Walnut St, Suite 607, Philadelphia, PA 19107 (E-mail: sloane.guy@jefferson.edu).

JTCVS Techniques 2021;10:90-1

2666-2507

Copyright (C) 2021 The Author(s). Published by Elsevier Inc. on behalf of The American Association for Thoracic Surgery. This is an open access article under the CC BY-NC-ND license (http://creativecommons.org/licenses/by-nc-nd/4.0/).

https://doi.org/10.1016/j.xjtc.2021.10.011

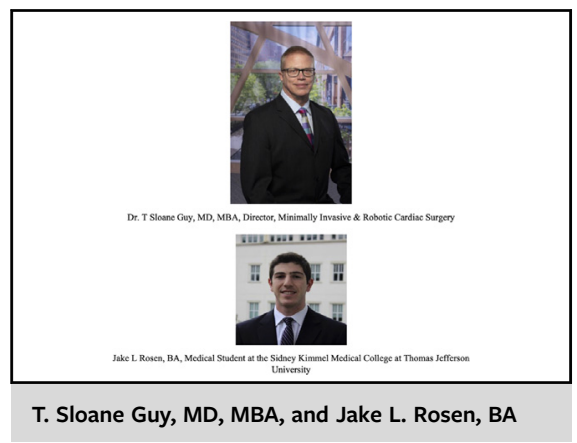

CENTRAL MESSAGE

Endoaortic balloon occlusion

(EABO) provides minimally inva-

sive access to clamp the aorta

during robotic mitral valve

surgery.

Furthermore, it is in our belief that the endoballoon provides distinct advantages relative to transthoracic crossclamping. First, contrary to the transthoracic clamp, the endoballoon applies a strictly transcatheter approach. Transthoracic clamping can lead to bleeding due to puncture of the aorta and has been shown to lead to more reoperations for bleeding relative to EABO. ${ }^{5}$ We are able to routinely place the cannulas, including the endoballoon, percutaneously without a cutdown. Whether needed or not, most surgeons currently perform generous thoracotomies to comfortably manage placement and removal of the antegrade cardioplegia catheter and also place the clamp when using a transthoracic clamp technique. Use of the EABO facilitates a completely endoscopic approach (visualization solely through an endoscope rather than direct visualization through incisions) to our robotic mitral valve surgeries. This method has been shown to be reproducible and effective in other high-volume centers as well. ${ }^{6}$ Conversely, transthoracic crossclamping has a risk of injury to the pulmonary artery or the left atrial appendage; aortic dissections are also potential complications. ${ }^{5}$ Superior vena cava obstruction can also complicate the operation, given its proximity to the clamp location; therefore, bicaval cannulation is mandatory with the transthoracic clamp technique. In the hands of a surgeon skilled in catheter-based techniques, these complications can be mitigated through the use of EABO. ${ }^{7}$ In addition, EABO is preferred in cases of a 
reoperation and where the aorta cannot be mobilized. ${ }^{8}$ Crossclamping is almost never a practical option in these reoperations because of adhesions at the ascending aorta ${ }^{9}$; surgeons can use EABO in these cases. ${ }^{3,10,11}$ The other option in reoperations is fibrillatory arrest, but this approach has been associated with a greater stroke risk due to increased probability of air embolism as well as a decreased repair rate over replacement. ${ }^{12}$

Cases of proximal and distal balloon migration have been noted as concerns with EABO, potentially obstructing cardioplegia and the brachiocephalic or carotid arteries, respectively. While mobilization is a noted concern, this pitfall has been mitigated with proper use of newer-generation intra-aortic balloons (Edwards IntraClude) and intraoperative management of balloon deployment. Transesophageal echocardiography is needed with catheter insertion and during balloon inflation and deflation; elimination of slack in the catheter at the time of inflation virtually eliminates migration. Continual transesophageal echocardiography monitoring can be applied to minimize procedural risk of aortic dissection or mobilization of emboli, which may be the consequence of femoral cannulation rather than the balloon itself. ${ }^{13}$ Active surveillance of aortic root and bilateral upper-extremity artery pressures are employed to gain insight into balloon positioning and potential displacement. ${ }^{13}$

Advancements in minimally invasive cardiac surgery enable patients to have procedures done with rapid recovery and minimal invasion. EABO accomplishes this goal without sacrificing the safety and integrity of the mitral valve procedure itself. As current and future cardiac surgeons further adopt endovascular techniques, surgeons may feel more comfortable with the prospect of using EABO over transthoracic clamping. Catheter usage and wire skills are paramount to the success of safe endoballoon deployment. We believe that EABO is conducive to the mitral valve surgeon of the future.

\section{References}

1. Bates M, Chitwood WR. Minimally invasive and robotic approaches to mitral valve surgery: transthoracic aortic crossclamping is optimal. J Thorac Cardiovasc Surg Tech. 2021;10:84-8.

2. Gammie JS, Chikwe J, Badhwar V, Thibault DP, Vemulapalli S, Thourani VH, et al. Isolated mitral valve surgery: the Society of Thoracic Surgeons adult cardiac surgery database analysis. Ann Thorac Surg. 2018;106:716-27.

3. Malvindi PG, Margari V, Mastro F, Visicchio G, Kounakis G, Favale A, et al. External aortic cross-clamping and endoaortic balloon occlusion in minimally invasive mitral valve surgery. Ann Cardiothorac Surg. 2018;7:748-54.

4. Khan H, Hadjittofi C, Uzzaman M, Salhiyyah K, Garg S, Butt S, et al. External aortic clamping versus endoaortic balloon occlusion in minimally invasive cardiac surgery: a systematic review and meta-analysis. Interact Cardiovasc Thorac Surg. 2018;27:208-14.

5. Barbero C, Krakor R, Bentala M, Casselman F, Candolfi P, Goldstein J, et al. Comparison of endoaortic and transthoracic aortic clamping in less-invasive mitral valve surgery. Ann Thorac Surg. 2018;105:794-8.

6. Murphy DA, Moss E, Binongo J, Miller JS, Macheers SK, Sarin EL, et al. The expanding role of endoscopic robotics in mitral valve surgery: 1,257 consecutive procedures. Ann Thorac Surg. 2015;100:1675-81; discussion 1681-2.

7. Atluri P, Goldstone AB, Fox J, Szeto WY, Hargrove WC. Port access cardiac operations can be safely performed with either endoaortic balloon or Chitwood clamp. Ann Thorac Surg. 2014;98:1579-83; discussion 1583-4.

8. Cetinkaya A, Ebraheem E, Bramlage K, Hein S, Bramlage P, Choi YH, et al. Long-term results of endoclamping in patients undergoing minimally invasive mitral valve surgery where external aortic clamping cannot be used-a propensity matched analysis. J Cardiothorac Surg. 2020;15:313.

9. Czesla M, Götte J, Weimar T, Ruttkay T, Doll N. Safeguards and pitfalls in minimally invasive mitral valve surgery. Ann Cardiothorac Surg. 2013;2:849-52.

10. Ailawadi G, Agnihotri AK, Mehall JR, Wolfe JA, Hummel BW, Fayers TM, et al Minimally invasive mitral valve surgery I: patient selection, evaluation, and planning. Innovations (Phila). 2016;11:243-50.

11. van der Merwe J, Casselman F, Stockman B, Vermeulen Y, Degrieck I, Van Praet F. Late redo-port access surgery after port access surgery. Interact Cardiovasc Thorac Surg. 2016;22:13-8.

12. Gammie JS, Zhao Y, Peterson ED, O'Brien SM, Rankin JS, Griffith BP. J. Maxwell Chamberlain memorial paper for adult cardiac surgery. Less-invasive mitral valve operations: trends and outcomes from the Society of Thoracic Surgeons adult cardiac surgery database. Ann Thorac Surg. 2010;90:1401-8. 1410.e1; discussion 1408-10.

13. Pisano C, Farinaccio A, Altieri C, Ajello V, Nardi P, Colella DF, et al. Imaging and monitoring in minimally invasive valve surgery using an intra-aortic occlusion device: a single center experience. J Thorac Dis. 2021;13:1011-9. 